\title{
Addendum: Kavian, F.; et al. Migration, Stress and the Challenges of Accessing Food: An Exploratory Study of the Experience of Recent Afghan Women Refugees in Adelaide, Australia. Int. J. Environ. Res. Public Health 2020, 17, 1379; doi:10.3390/ijerph17041379
}

\author{
Foorough Kavian ${ }^{1}$, Kaye Mehta ${ }^{1}$, Eileen Willis ${ }^{1}{ }^{(0}$, Lilian Mwanri ${ }^{2}{ }^{(}$, Paul Ward ${ }^{2}(\mathbb{D}$ and \\ Sue Booth ${ }^{2, *}$ \\ 1 College of Nursing and Health Sciences, Flinders University, GPO Box, Adelaide 2100, Australia; \\ Foorough.Kavian@flinders.edu.au (F.K.); Kaye.Mehta@flinders.edu.au (K.M.); \\ Eileen.Willis@flinders.edu.au (E.W.) \\ 2 College of Medicine \& Public Health, Flinders University, GPO Box, Adelaide 2100, Australia; \\ Lillian.Mwanri@flinders.edu.au (L.M.); Paul.Ward@flinders.edu.au (P.W.) \\ * Correspondence: sue.booth@flinders.edu.au; Tel.: +61-872-218-464
}

Received: 28 June 2020; Accepted: 29 June 2020; Published: 3 July 2020

In the original version of our article [1], insufficient details were given in recognition of the support and funding from our Canadian collaborators. We apologize for the original error. To correct this oversight, the acknowledgements have been altered in the "Funding" section to more appropriately acknowledge the contribution of Hassan Vatanparast and Mahasti Khakpour, who conceptualised the grant and broader research studies, both quantitative and qualitative.

Funding: The authors would like to gratefully acknowledge funding support from the University of Saskatchewan, Canada as part of a larger research grant received from the Social Sciences and Humanities Research Council of Canada (346675 Fund \#418151). We would also like to acknowledge the contributions of Hassan Vatanparast and Mahasti Khakpour, who conceptualised the grant and broader research studies, both quantitative and qualitative.

\section{Reference}

1. Kavian, F.; Mehta, K.; Willis, E.; Mwanri, L.; Ward, P.; Booth, S. Migration, Stress and the Challenges of Accessing Food: An Exploratory Study of the Experience of Recent Afghan Women Refugees in Adelaide, Australia. Int. J. Environ. Res. Public Health 2020, 17, 1379. [CrossRef] [PubMed]

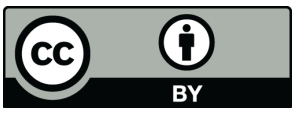

(C) 2020 by the authors. Licensee MDPI, Basel, Switzerland. This article is an open access article distributed under the terms and conditions of the Creative Commons Attribution (CC BY) license (http://creativecommons.org/licenses/by/4.0/). 